\title{
Microbiology and Clinical Implications of Dental Caries - A Review
}

\author{
Sachidananda Mallya P. ${ }^{1}$, Shrikara Mallya²
}

${ }^{1}$ Department of Oral and Maxillofacial Pathology and Oral Microbiology, Nitte (Deemed to Be University), AB Shetty Memorial Institute of Dental Sciences (ABSMIDS), Mangalore, Karnataka, India. ${ }^{2}$ Department of Microbiology, AJ Institute of Medical Sciences and Research Centre, Rajiv Gandhi University of Health Sciences, Bengaluru, Karnataka, India.

\section{ABSTRACT}

Dental caries is a chronic infection caused by normal oral microbial flora. Even though there are several types of bacteria in the oral cavity, only a certain species of bacteria can initiate dental caries and periodontal infection. The bacteria which are most frequently associated with dental caries were Streptococcus mutans, Lactobacillus and Actinomycetes. These are gram positive bacteria which are acidogenic and aciduric. Lactobacillus is not the caries initiator but plays an important role in the progression of caries. The prerequisite in the aetiology of dental caries are cariogenic bacteria, fermentable carbohydrates, a susceptible tooth, the host and the time. The caries lesion is the result of demineralization of enamel and or dentin by acids produced by aciduric bacteria as they metabolize dietary carbohydrates. The consequences of these infections can vary according to immunological resistance of the patient as well as the resistance of some microorganisms to the most common antimicrobial agents. Factors to be taken into consideration in the treatment are the patient's history, microbial virulence factors, and maintaining or suppression of aetiological factors. Severe dental caries may cause chronic inflammatory response in the endothelial coronary cells through bacterial invasion and also can induce atherosclerosis which can increase the risk factor for the development of chronic heart disease. Organisms causing dental caries have been implicated as causative agents for bacterial endocarditis. Systemic antibiotics showed potential efficacy in the prevention or treatment of dental caries. The present review spotlights the current knowledge on the microbiology and clinical implications of dental caries.

\section{KEY WORDS}

Dental Caries, Cariogenic Bacteria, Biofilm, Antimicrobial Agents, Endocarditis

\section{Corresponding Author:} Dr. Sachidananda Mallya P, Nitte (Deemed to Be University), $A B$ Shetty Memorial Institute of Dental Sciences (ABSMIDS), Mangalore, Karnataka, India.

E-mail: mallyapsachin@gmail.com

DOI: $10.14260 / j e m d s / 2020 / 805$

How to Cite This Article:

Mallya PS, Mallya S. Microbiology and clinical implications of dental caries - a review. J Evolution Med Dent Sci 2020;9(48):3670-3675, DOI: $10.14260 /$ jemds $/ 2020 / 805$

Submission 04-08-2020,

Peer Review 14-10-2020,

Acceptance 20-10-2020,

Published 30-11-2020.

Copyright (C) 2020 Sachidananda Mallya P. et al. This is an open access article distributed under Creative Commons Attribution License [Attribution 4.0 International (CC BY 4.0)] 


\section{BACKGROUND}

Dental caries is a chronic, localized infection in which there is an altered tooth structure due to loss of chemicals resulting from the metabolic activity and also occurrence of dental biofilm on the surface of the tooth. ${ }^{1}$ This change is reversible in its early stages. The multiple factors that determine the outcome of dental caries are saliva, sugar dietary consumptions and exposure to fluoride which influence the dynamic balance between the demineralisation and remineralisation processes. ${ }^{2}$ Dental caries has now been included in a group of conditions like cancer or diabetes which has multifactorial aetiology with no single causation mechanism. ${ }^{3}$ The factors that can vary prevalence pattern and severity of dental caries are age, sex, race, socio-economic status, geographical location, food habit and habits of oral hygiene either in the same country or in various parts of the world. ${ }^{4}$ The interest in the use of antibacterial agents for the treatment and prevention of dental diseases has increased considerably in the world. ${ }^{5}$ The emergence of antibiotic resistance has been identified due to inappropriate prescription and practice of antibiotic use In the recent years, dentists and dental professionals has shifted their interest from narrow spectrum antibiotic prescriptions to broadspectrum aminopenicillins due to enhancement of bacterial isolates resistant to the former antibiotics in prescription practices. The development of resistance in antibiotics and also increased expenses of management and drugs used has resulted in increase of morbidity in dental caries. ${ }^{6}$ The individual's microflora is extremely convoluted and extraordinary group of microorganisms forming various associations in the mouth thereby residing more than 700 dissimilar species $^{7}$ Bacteria are considerably the most dominant form of microorganisms existing in the human oral cavity and few examples are S. Sanguis, S. Mitis, S. Mutans, S. Salivarius, L. Acidophilus, L. Salivarius, L. Casei, Staphylococcus spp, Eubacterium spp, Neisseria spp, Actinomyces spp, PeptoStreptococcus spp, Micrococcus spp, etc. Among them Streptococcus alone forms the biggest association in the oral cavity. ${ }^{8}$

\section{History of Dental Caries}

According to the archaeological evidence human race lives with dental caries for millions of years. Australopithecus suffered from cavities. Caries was found even during the Palaeolithic and Mesolithic ages. ${ }^{9}$ There was a sharp increase in the prevalence of dental caries in 1850 which was due to appearance of sugarcane, bread and sweetened tea in the western world. ${ }^{10}$ Even though James Kilian Clarke isolated Streptococcus mutans from a carious lesion in 1924, the real interest in this bacteria was generated in 1960s when researchers began studying dental caries.11 Oral microorganisms start to colonize an infant's mouth soon after birth. The numbers of oral bacteria increase gradually from exposure with microbial sources from the external environment Streptococcus salivarius, Streptococcus mitis, Streptococcus oralis have been identified as the first and most dominant oral microbes to colonize the oral cavities of the newborn infants. The number and type of organisms of the oral microflora increase following the eruption of primary teeth. $^{12}$ Historically, Lactobacillus was the first known microorganism associated with dental caries development. ${ }^{13}$ They appear during the first years of a child's life and are present in high numbers in saliva, on the dorsum of the tongue, mucous membranes, the hard palate, in dental plaque and, in fewer numbers, on tooth surfaces. ${ }^{14}$ Microorganisms in the form of dental plaque are a prerequisite for the development of dental caries. The main bacteria that cause dental caries among these is Streptococcus mutans. The two species of Streptococcus most commonly found in humans are Streptococcus mutans (serotype c / e / f) and Streptococcus sobrinus (serotype d / g).15,16

\section{Factors Responsible for Cariogenicity of Streptococcus mutans}

Their number in saliva and at site of the lesions, recovered from the site before the formation of caries, sugar metabolism and its efficient capability of transport, acidogenic and aciduric property, the effect of $\mathrm{pH}$ on growth and metabolism, production of EPS and IPS.

\section{Role of Streptococcus mutans}

Ability to initiate and maintain microbial growth and to continue acid production at low $\mathrm{pH}$ values, rapid metabolism of sugars to lactic and other organic acids, ability to attain the critical $\mathrm{pH}$ for enamel demineralization more rapidly than other common plaque bacteria, ability to produce Intracellular Poly-Saccharides (IPSs) as glycogen, which may act as a food store for use when dietary carbohydrates are low, immunization of animals with specific $S$. mutans serotypes significantly reduces the incidence of caries. ${ }^{15,16}$

\section{Pathogenicity of Streptococcus mutans}

Streptococcus mutans gained importance within medical field in late 1950's. In mid-1960's, clinical and animal experiment studies showed Streptococcus mutans as an important causative agent in dental caries. The main habitat of Streptococcus mutans is human oral cavity, more specifically the dental plaque which formed biofilm on all surfaces of the tooth. ${ }^{17}$ The cariogenic potential of Streptococcus mutans lies in 3 main attributes.

1. The permanent colonization of hard surfaces due to synthetization of large number of extracellular polymers of glucans from the sugar sucrose

2. The ability to transport and metabolize a large number of carbohydrates into organic acids. (acidogenicity)

3. The ability to survive in environmental stress conditions, particularly low $\mathrm{pH}$. (aciduricity) ${ }^{18}$

Streptococcus mutans can alter the local environment by forming EPS-rich and low $\mathrm{pH}$ conditions which makes a favourable environment for acidogenic and aciduric bacteria and thus can help other bacteria in the formation of dental caries. ${ }^{19}$ The number of Streptococcus mutans varies in different areas in the oral cavity, with a large bacterial load seen on the dorsum of tongue. There are three steps involved in the formation of dental plaque. The first step, salivary molecules are adsorbed to the enamel and enamel is coated with complex mixture of components that include glycoproteins, acidic proline rich proteins, bacterial cell debris, exoproducts, mucins and sialic acid. The second step is 
bacterial interaction with this acquired pellicle via several specific cell to surface interactions with the formation of biofilms of primary colonizers like Streptococcus sanguis and Actinomyces viscosus. The third step, the other bacterial species like Streptococcus mutans adhere to the primary colonizers by cell to cell interactions which forms biofilm on the tooth which is known as dental plaque.20,21 Streptococcus mutans secretes glucosyl transferase on its cell wall, which allows the bacteria to produce polysaccharide (glucan) from sucrose which are responsible for the ability of the bacteria to aggregate with one another and adhere to tooth enamel to form biofilm. Streptococcus mutans produces 3 types of glucosyl transferases (gtfB, gtfC, gtfD) whose cooperative action is essential for adherence of bacterial cells. ${ }^{22}$

One of the principal virulence factors of Streptococcus mutans is production of bacteriocins (peptide antibiotics) referred to as mutacins. Two component signal transduction systems are commonly utilized by Streptococcus mutans to regulate bacteriocin gene expression and are also related to biofilm formation.23 Streptococcus mutans also regulate diverse physiological processes in a cell density-dependent manner known as quorum sensing, which they utilize to modulate environmental stress responses. ${ }^{24}$

\section{Pathogenicity of Lactobacillus}

Even though Lactobacillus are mainly considered as nonpathogenic, few Lactobacillus species are found in caries lesions. They are usually not found in caries free children. They represent a major contributor to caries progression, even though they are not caries initiators. The main characteristic feature of Lactobacillus is their ability to produce lactic acid as a by-product of glucose metabolism. Lactobacillus is considered the second common cariogenic bacteria of oral flora. The species of Lactobacillus that are mostly associated with pathogenesis of dental caries are Lactobacillus gassier, Lactobacillus fermentum and Lactobacillus casei. ${ }^{25}$ The two cariogenic properties of lactobacillus are adhesion and acid production. The cell surface hydrophobicity of lactobacillus is mainly due to the $S$ layer protein present in their cell wall. The exopolysaccharide produced by Lactobacillus species is a key factor in the formation of biofilm. These bacteria use two types of metabolism methods - homo-fermentative and heterofermentative to produce lactic acid and acetic acid. The Lactobacillus is the main organism in caries progression because of their large numbers in carious lesion and their acidogenic and aciduric properties. It is excellent acid tolerant bacteria and they can survive below $\mathrm{pH} 4.5$. They get attached to dental plaque and start to dematerialize the tooth enamel.26,27

\section{Treatment of Dental Caries with Antimicrobials}

Dental caries is a disease caused by dysbiotic microorganism which also produces biofilm and characterized by prolonged periods of acidic $\mathrm{pH}$ in the oral cavity that results in net loss of mineral from the teeth. An antibacterial treatment should be considered as part of the overall management if the patient has a issue of bacterial load or metabolic dysfunction of the biofilm. The main antibacterial agent used for dental caries has been chlorhexidine gluconate $(0.12 \%)$ rinse which acts as an antiplaque agent. The chlorhexidine molecule acts on the cell wall of bacteria and disrupts its integrity. It is necessary to do the bacterial testing before the conduct of clinical trial to know the frequency of use of chlorhexidine rinse. Sodium hypochlorite rinse can also be used as an antiplaque agent, an antimicrobial agent which acts on the cell wall and also agitates the biofilm. ${ }^{28}$ In the very early stages it is possible to restore tooth enamel and sometimes even can reverse cavity formation by using fluoride. A silver based formulations (SBF and nano silver) has also shown antimicrobial activity against the predominant cariogenic flora particularly from dentin lesions. ${ }^{29}$ The number of caries in infants can be reduced by local application of $10 \%$ povidone iodine solution to the dentine of the infant every second month shown by a double blind placebo controlled clinical trial. The iodine is released slowly from povidone iodine which allows a long period antibacterial effects. ${ }^{30,31}$ Xylitol is a five-carbon sugar alcohol which has an antimicrobial activity. Daily xylitol wipe application significantly reduced the caries incidence in young children as compared with wipe without xylitol. The use of xylitol wipes may be a useful adjunct for caries control in infants. ${ }^{32}$ Streptococcus mutans is susceptible to two active ingredients glycyrrhizol A and B of the Chinese herb Glycyrrhiza uralensis. ${ }^{33}$ The extract of leaves of Bridelia scandens is highly effective against Streptococcus mutans and Lactobacillus. ${ }^{34}$ The antibiotics that act specifically on cariogenic microorganisms is more ideal for treatment of dental caries than systemic antibiotic .At the same time indiscriminate use of antibiotics can lead to development of resistance or persistence. To avoid the development of antibiotic resistance, the use of a combination of two or more antibacterial agents is a practical and fast means of developing new therapy for dental caries. 35 The most commonly used antibiotics in dental practice was amoxicillin, penicillin $\mathrm{V}$, metronidazole and the combination of amoxicillin and clavulanic acid. ${ }^{36}$

\section{Role of Saliva}

Saliva maintain the normal oral flora and tooth surface integrity through bacterial clearance, buffering capacity, direct antibacterial activity and remineralization. When saliva flow is reduced, oral health problems such as dental caries and oral infections develop. ${ }^{37}$

Complications of dental caries include abscess, fistula, cellulitis, odontogenic cysts, actinomycosis, craniofacial thrombophlebitis, maxillary sinusitis, septicaemia and osteomyelitis. The result of these infections can change according to immunological status of the patient as well as the microbial resistance to the commonly used antibiotics. ${ }^{38}$

The three mechanisms connecting oral infections to secondary systemic effects-

- Transient bacteraemia resulting in metastatic spread of infection from oral cavity.

- The circulating toxins produced by oral microorganism which can cause metastatic injury.

- The immunological injury caused by oral microorganisms. Can result in metastatic inflammation.

Periodontitis as a major oral infection may affect the host's susceptibility to systemic disease in three ways: by shared risk factors, subgingival biofilms acting as reservoir of gram negative bacteria and the periodontium acting as a 
reservoir of inflammatory mediators such as cytokines. ${ }^{39}$ Cardiovascular diseases associated with dental caries are atherosclerosis and myocardial infarction which occurs as result of complex set of genetic and environmental factors. The factors that give rise to cardiovascular diseases associated with dental caries can be classified into genetic factors like obesity, lipid metabolism, diabetes, hypertension and environmental factors like diet, smoking socioeconomic status. ${ }^{39}$ The oral origin of Streptococcus mutans is evident from its simultaneous presence in the cardiovascular region and in the dental plaque. ${ }^{40}$ Streptococcus mutans is known to be associated with bacteraemia and infective endocarditis. ${ }^{41}$ Streptococcus mutans strains are classified into 4 serotypes C, $\mathrm{E}, \mathrm{F}$ and $\mathrm{K}$ based on their cell surface rhamnose-glucose polymers. ${ }^{42}$ A High frequency of serotype K strain has been identified in Streptococcus mutans positive extirpated heart valve specimen from infective endocarditis patients. ${ }^{43}$ The most important factors in the pathogenesis of infective endocarditis due to Streptococcus mutans is platelet aggregation. The fibrinogen binding affinity of Streptococcus mutans is also considered to be a virulence factor for infective endocarditis. These two properties are more commonly found in serotype $\mathrm{K}$ strains. ${ }^{44}$ Infective endocarditis due to lactobacillus is relatively uncommon as compared to infective endocarditis due Streptococcus mutans. Lactobacillus also have been found to aggregate platelets, bind both fibronectin and fibrinogen and adhere to collagen types 1 and 5, which compose the extracellular matrix of endothelial cells. ${ }^{45} \mathrm{~A}$ recent study showed that the bacteria that cause dental caries are linked to an immune response which may be protective against cancer such as head and neck squamous cell carcinoma. ${ }^{46}$

\section{Laboratory Diagnosis}

The specimen collected for the identification of Streptococcus mutans and Lactobacillus are the swabs from the carious tooth and saliva. Swab must be collected before commencement of antibiotic therapy. The swab should be transported to the laboratory and identified by staining methods, culture on appropriate medium, biochemical and immunological tests. Nested PCR (polymerase chain reaction) is able to identify Streptococcus mutans more rapidly and directly in saliva. ${ }^{47}$

\section{Prevention and Treatment}

By using chlorhexidine in mouth washes which holds antibacterial properties for cleaning of mouth. Antibiotics like penicillin, vancomycin, erythromycin and combination of amoxicillin and clavulanic acid can be used. ${ }^{48}$ The local use of monoclonal antibodies is effective against the antigens of Streptococcus mutans which can also prevent recolonization of the organism. ${ }^{49}$ The technique of bacterial interference can be implemented by using less virulent mutants of Streptococcus mutans which are harmless and are highly competitive in place of wild types of Streptococcus mutans strains. ${ }^{50}$

\section{CONCLUSIONS}

Dental caries is one of the most common and expensive diseases that can affect individual's health and quality of life considerably. This review highlights the significant role of Streptococcus and Lactobacillus in the development of dental caries. Important methods used to reduce the risk of dental caries usually involve decreasing the growth or activity of Streptococcus mutans. Several risk factors of dental caries are also documented in this review. It is predicted that diagnostic, preventive and treatment strategies directed towards specific bacterial species will not be universally effective because of polymicrobial nature of dental caries. The caries lesion is a result of the imbalance in the equilibrium between mineral loss of tooth and biofilm fluid usually results in caries lesion. Caries is an endemic and potentially both preventable and curable. Development of increased resistance by the antibiotics currently used in dental practice hinders the prevention of oral bacterial growth, adhesion and colonization. In order to be secured from these troublesome infections it is necessary to take necessary precautions like brushing twice a day, reduction in intake of sucrose rich food, regular mouth washing and flossing.

Financial or other competing interests: None.

Disclosure forms provided by the authors are available with the full text of this article at jemds.com.

\section{REFERENCES}

[1] Selwitz RH, Ismail AI, Pitts NB. Dental caries. Lancet 2007;369(9555):51-9.

[2] Featherstone JDB. The continuum of dental caries-evidence for a dynamic disease process. J Dent Res 2004;83:C39-42.

[3] Fejerskov 0. Changing paradigms in concepts on dental caries: consequences for oral health care. Caries Res 2004;38(3):182-191.

[4] Petersen PE, Bourgeois D, Ogawa $\mathrm{H}$, et al. The global burden of oral diseases and risks to oral health. Bull World Health Organ 2005;83(9):661-9.

[5] Sweeney LC, Dave J, Chambers PA, et al. Antibiotic resistance in general dental practice--a cause for concern? J Antimicrob Chemother 2004;53(4):567-76.

[6] De Marchi RJ, Hugo FN, Padilha DMP, et al. Edentulism, use of dentures and consumption of fruit and vegetables in south Brazilian community-dwelling elderly. J Oral Rehabil 2011;38(7):533-40.

[7] Metwalli KH, Khan SA, Krom BP, et al. Streptococcus mutans, Candida albicans, and the human mouth: a sticky situation. PLOS Pathog 2013;9(10):e1003616.

[8] Bhatia R, Ichhpujani RL. Microbiology for dental students. $3^{\text {rd }}$ edn. New Delhi: Jaypee Brothers 2003.

[9] Kuttler Y. Microscopic investigation of root apexes. J Am Dent Assoc 1955;50(5):544-52.

[10] Yang ZP, Yang SF, Lin YC, et al. C-shaped root canals in mandibular second molars in a Chinese population. Endod Dent Traumatol 1988;4(4):160-3. 
[11] Melton DC, Krell KV, Fuller MW. Anatomical and histological features of C-shaped canals in mandibular second molars. J Endodon 1991;17(8):384-8.

[12] Pearce C, Bowden GH, Evans M, et al. Identification of pioneer viridans Streptococci in the oral cavity of human neonates. J Med Microbiol 1995;42(1):67-72.

[13] Lewkowicz X. Erch Med Expt et anat path (Paris) 1901;13:633-60.

[14] Badet C, Thebaud NB. Ecology of Lactobacillus in the oral cavity: a review of literature. Open Microbiol J 2008;2:3848.

[15] Marsh P, Martin M, Lewis M, et al. Plaque mediated diseases - dental caries and periodontal diseases. In: Oral microbiology. $5^{\text {th }}$ edn. Churchil Livingstone 2009:104-17.

[16] Bagg J, Macfarlane TW, Poxton IR, et al. Dental caries in essentials of microbiology for dental students. $2^{\text {nd }}$ edn. Oxford University Press 2006:238-48.

[17] Loesche WJ. Role of Streptococcus mutans in human dental decay. Microbiol Rev 1986;50(4):353-80.

[18] Lemos JA, Burne RA. A model of efficiency: stress tolerance by Streptococcus mutans. Microbiology 2008;154(Pt 11):3247-55.

[19] Lemos JA, Palmer SR, Zeng L, et al. The Biology of Streptococcus mutans. Microbiol Spectr 2019;7(1).

[20] Lamont RJ, Demuth DR, Davis CA, et al. Salivaryagglutinin-mediated adherence of Streptococcus-mutans to early plaque bacteria. Infect Immun 1991;59(10):3446-50.

[21] Marsh P. Dental plaque as a biofilm and a microbial community - implications for health and disease. BMC Oral Health 2006;6(Suppl 1):S14.

[22] Ooshima T, Matsumura M, Hoshino T, et al. Contribution of three glucosyltransferase tosucrose-dependent adherence of Streptococcus mutans. J Dent Res 2001;80(7):1672-7.

[23] Matsumoto-Nakano M. Role of Streptococcus mutans surface proteins for biofilm formation. Jpn Dent Sci Rev 2018;54(1):22-9.

[24] Bassler BL. How bacteria talk to each other: regulation of gene expression by quorum sensing. Curr Opin Microbiol 1999;2(6):582-7.

[25] Ahirwar SS, Gupta MK, Snehi SK. Dental caries and Lactobacillus: role and ecology in the oral cavity. International Journal of Pharmaceutical Sciences and Research 2019;10(11):4818-29.

[26] Van Houte J, Aasenden R, Peebles TC. Lactobacillus in human dental plaque and saliva. J Dent Res 1981;60(1):25.

[27] del Carmen Ahumada M, Bru E, Colloca ME, et al. Evaluation and comparison of lactobacillus characteristics in the mouths of patients with or without cavities. J Oral Sci 2003;45(1):1-9.

[28] Featherstone JDB, White JM, Hoover CI, et al. A randomized clinical trial of anticaries therapies targeted according to risk assessment (caries management by risk assessment). Caries Res 2012;46(2):118-29.

[29] Fakhruddin KS, Egusa H, Ngo HC, et al. Clinical efficacy and the antimicrobial potential of silver formulations in arresting dental caries: a systematic review. BMC Oral Health 2020;20:160.

[30] Lopez L, Berkowitz R, Spiekerman C, et al. Topical antimicrobial therapy in the prevention of early childhood caries: a follow-up report. Pediatr Dent 2002;24(3):204-6.

[31] Tam A, Shemesh M, Wormser U, et al. Effect of different iodine formulations on the expression and activity of Streptococcus mutans glucosyltransferase and fructosyltransferase in biofilm and planktonic environments. J Antimicrobial Chemotherapy 2006;57(5):865-71.

[32] Zhan L, Cheng J, Chang P, et al. Effects of xylitol wipes on cariogenic bacteria and caries in young children. J Dent Res 2012;91(7 Suppl):S85-90.

[33] He J, Chen L, Heber D, et al. Antibacterial compounds from Glycyrrhiza uralensis. J Nat Prod 2006;69(1):121-4.

[34] Mallya S, Mallya S, Rao V. Antimicrobial properties of bridelia scandens against oral pathogens: in vitro study. Nitte University Journal of Health Science 2018;8(2):3242.

[35] Wu Y, Hu T. Research progress on fluoride-resistant strains of Streptococcus mutans. International Journal of Stomatology 2012;39:342-5.

[36] Dinsbach NA. Antibiotics in dentistry: bacteremia, antibiotic prophylaxis, and antibiotic misuse. Gen Dent 2012;60(3):200-7.

[37] Stookey GK. The effect of saliva on dental caries. J Am Dent Assoc 2008;139 Suppl:S11-7.

[38] Deroux E. Complications des infections dentaires [Complications of dental infections]. Rev Med Brux 2001;22(4):A289-95.

[39] Li X, Kolltviet MK, Tronstad L, et al. Systemic diseases caused by oral infection. Clin Microbiol Rev 2000;13(4):547-58.

[40] Nakano K, Inaba H, Nomura $R$, et al. Detection of cariogenic Streptococcus mutans in extirpated heart valve and atheromatous plaque specimens. J Clin Microbiol 2006;44(9):3313-7.

[41] Nakano K, Nomura R, Ooshima T. Streptococcus mutans and cardiovascular diseases. Japanese Dental Science Review 2008;44:29-37.

[42] Hamada S, Slade HD. Biology, immunology, and cariogenicity of Streptococcus mutans. Microbiol Rev 1980;44(2):331-84.

[43] Nakano K, Nomura R, Nemoto H, et al. Detection of novel serotype k Streptococcus mutans in infective endocarditis patients. J Med Microbiol 2007;56(Pt 10):1413-5.

[44] Nomura R, Otsugu M, Naka S, et al. Contribution of the interaction of Streptococcus mutans serotype k strains with fibrinogen to the pathogenicity of infective endocarditis. Infect Immun 2014;82(12):5223-34.

[45] Harty DW, Oakey HJ, Patrikakis M, et al. Pathogenic potential of lactobacillus. Int J Food Microbiol 1994;24(12):179-89.

[46] Tezal M, Scannapieco FA, Wactawski-Wende J, et al. Dental caries and head and neck cancers. JAMA Otolaryngol Head Neck Surg 2013;139(10):1054-60.

[47] Oho T, Yamashita Y, Shimazaki Y, et al. Simple and rapid detection of Streptococcus mutans and Streptococcus sobrinus in human saliva by polymerase chain reaction. Oral Microbiol Immunol 2000;15(4):258-62.

[48] El Sherbiny GM. Control of growth Streptococcus mutans isolated from saliva and dental caries. Int J Curr Microbiol App Sci 2014;3(10):1-10. 
[49] Samaranayake L. Essential microbiology for dentistry. $3^{\text {rd }}$ edn. Elsevier: Churchill Livingstone 2007.
[50] Marsh PD, Martin MV. Oral microbiology. $5^{\text {th }}$ edn. Elsevier 2012. 